\title{
FONTES, GESTÃO E DIVULGAÇÃO CIENTÍFICA: relato do desenvolvimento de uma ferramenta de busca para Imprensa
}

SOURCES, MANAGEMENT AND SCIENTIFIC DISSEMINATION: report on the development of a search tool for the Press

FUENTES, GESTIÓN Y DIFUSIÓN CIENTÍFICA: informe sobre el desarrollo de una herramienta de búsqueda para Prensa

\section{Rodrigo Eduardo Botelho-Francisco}

Livre-Docente em Informação e Tecnologia pela Universidade de São Paulo (USP). Professor do Departamento de Ciência e Gestão da Informação da Universidade Federal do Paraná (UFPR). Integrante da Agência Escola UFPR. rodrigobotelho@ufpr.br.

0000-0002-4772-9398

\section{Fabia Cristiane loscote}

Doutoranda e Mestra em Comunicação pela UFPR. Jornalista formada pela Universidade Tuiuti do Paraná (UTP). Bolsista Capes; bolsista Agência Escola UFPR (2018-2020). fabia.ioscote@ufpr.br.

\section{0-0002-6318-026X}

\section{Antonio Rodrigues Barros}

Mestre em Ciência, Gestão e Tecnologia da Informação e Tecnólogo em Tecnologia da Informação pela UFPR. Servidor Público Técnico de Tecnologia da Informação do quadro permanente da UFPR. Bolsista técnico na Agência Escola UFPR. antonio@ufpr.br.

\section{0-0003-1929-1402}

\section{Matheus Dias Galdino Soares}

Mestrando em Comunicação pela UFPR. Jornalista formado pela Universidade Estadual de Ponta Grossa (UEPG). Bolsista Agência Escola UFPR (2020-2021). aomatheusao@gmail.com.

\section{0-0002-3078-3005}

Correspondência: UFPR/SA/DECIGI, Av. Prefeito Lothário Meissner, 632, $1^{\circ}$ andar, Jardim Botânico, Curitiba/PR, CEP 80210-170 - Brasil.
Recebido em: 16.02.2021

Aceito em: 16.04.2021.

Publicado em: 01.07.2021.

\section{RESUMO:}

Este artigo tem por objetivo apresentar um relato do desenvolvimento do Guia de Fontes @UFPR, uma ferramenta para busca de informação científica criada no âmbito da Agência Escola de Comunicação Pública e Divulgação Científica e Cultural (AE) da Universidade Federal do Paraná (UFPR). Neste contexto, 0 trabalho discute a informação e a gestão de conteúdo científica sob um ponto de vista interdisciplinar e descreve o desenvolvimento do software contemplando o Jornalismo, a Gestão da Informação e a Compuação, areas do conhecimento nas quais estão pautados os princípios metodológicos do Guia de Fontes @UFPR. Por fim, o trabalho apresenta os resultados à luz da Divulgação Científica.

PALAVRAS-CHAVES: Fontes de Informação; Gestão de Conteúdo; Desenvolvimento web; Jornalismo; Divulgação Científica .

\section{Introdução}

Este artigo tem como objetivo apresentar um relato de desenvolvimento do Guia de Fontes @UFPR ${ }^{1}$, uma ferramenta de busca de fontes de informação científica desenvolvida pela Agência Escola de Comunicação Pública e Divulgação Científica e Cultural (AE) da Universidade Federal do Paraná (UFPR). Especificamente, visa discutir a informação científica de um ponto de vista interdisciplinar; debater a gestão de

\footnotetext{
${ }^{1}$ Disponível em www.guiadefontes.ufpr.br.
} 
conteúdos desta natureza; e descrever o desenvolvimento do software propriamente dito.

Ferramenta de busca é entendida, neste artigo, como um instrumento para localização de recursos informacionais (CENDÓN, 2001), desenhada para prover resultados a partir de palavras-chave definidas por um interagente em documentos ou em uma base de dados específica ou na Internet. Também conhecidas como motores de busca ou diretórios são popularmente reconhecidas nos serviços providos por plataformas como, por exemplo, Google e Yahoo.

Do ponto de vista da Imprensa, um Guia de Fontes é um motor de busca utilizado no processo de localização de especialistas que possam colaborar no processo de produção e redação de notícias ou reportagens, concedendo entrevista ou informações que permitam ao jornalista entender conceitos ou fatos, além de confrontar opiniões. Neste sentido, a fonte é considerada uma autoridade em relação ao tema que é consultada.

No jornalismo, as fontes são um assunto de fundamental seriedade, cujo cultivo custa tempo e dinheiro aos veículos e profissionais de comunicação. Pinto (2009) relata que estes possuem bancos de dados próprios com as fontes mais acessíveis. Para Traquina (2005), existe uma rede noticiosa na qual as fontes humanas se inserem e se distribuem. Logo, um guia que reúna estes agentes de forma mais lógica e de fácil acesso se torna um relevante aliado da eficiência nas rotinas profissionais, potencializando o alcance da rede noticiosa.

A construção de Guias de Fontes, no entanto, esbarra em problemas como disponibilidade e fiabilidade de dados, atualização e custos. Isto porque depende da reunião de informações sobre pessoas e suas especialidades de forma constante, o que requer a inserção e atualização manual destes dados em uma base estruturada ou sua obtenção a partir de outras fontes de forma interoperável. O fato é que nem sempre as detentoras das informações estão disponíveis para participar deste processo de cadastro e atualização num ritmo razoavelmente adequado. Por outro lado, envolver terceiros no processo tem um alto custo e requer muito cuidado para garantir a qualidade do cadastro.

Frente a esta problemática, o Guia de Fontes @UFPR foi desenvolvido pela Agência Escola numa perspectiva de utilização de dados científicos abertos, uma vez que se pauta no uso interoperável de dados do Currículo Lattes, "um padrão nacional no registro da vida pregressa e atual dos estudantes e pesquisadores do país, e é hoje 
adotado pela maioria das instituições de fomento, universidades e institutos de pesquisa do País" (CNPq, [s.d.]).

A AE, mantenedora do Guia de Fontes @UFPR, é um projeto técnico-científico, envolvendo o Setor de Artes, Comunicação e Design (SACOD), a Superintendência de Comunicação e Marketing (SUCOM) e a Fundação da Universidade Federal do Paraná (Funpar), com objetivo de realizar um trabalho de posicionamento da Universidade como ator relevante no cenário regional, nacional e internacional ao conferir maior visibilidade à produção científica e cultural nela desenvolvida ou por ela estimulada.

Nesta perspectiva, a proposta do Guia de Fontes @UFPR justifica-se tendo em vista a abordagem da Comunicação Pública da $A E$, que mantém como princípio a valorização da informação de interesse público, que interfere no desenvolvimento social. Além disso, está pautada na perspectiva da inovação tecnológica, um dos três eixos de atuação da $A E$, voltado para o desenvolvimento e aprimoramento de soluções digitais para Gestão da Informação, facilitando o acesso dos públicos interno e externo às informações sobre a UFPR.

Do ponto de vista metodológico, o desenvolvimento do Guia de Fontes @UFPR está centrado numa visão interdisciplinar, envolvendo conhecimentos do Jornalismo, da Gestão de Conteúdos e da Computação. Neste artigo, por sua vez, para apresentar o relato, pauta-se a discussão na perspectiva das fontes de informação por estas diferentes áreas do conhecimento, nos diferentes aspectos envolvidos na representação e recuperação da informação e em aspectos selecionados do processo de desenvolvimento de software.

\section{Fontes de Informação}

As fontes de informação variam de acordo com os seus usos, intencionalidades, características e formatações. O Guia de Fontes @UFPR busca, neste sentido, utilizar fontes de acordo com suas definições pela Ciência da Informação $(\mathrm{Cl})$, pelo Jornalismo, pela Ciência da Informação $(\mathrm{Cl})$ e pela Computação.

Embora o Guia de Fontes @UFPR tenha como principal função permitir aos jornalistas e repórteres um contato agilizado com pesquisadores especializados das diversas áreas do conhecimento, a plataforma é pautada pela ideia de Fontes de Informação, na medida em que reúne diversos dados de variadas origens e suportes para oferecer uma solução aos desafios do trabalho midiático. 
$\mathrm{Na} \mathrm{Cl}$, as fontes de informações são as pessoas, as instituições e as publicações que podem ser classificadas pela perspectiva da localização em primárias, secundárias e terciárias (ALBRECHT \& OHIRA, 2000). As primárias são as informações originais, oriundas de textos de artigos, teses, dissertações, livros e outras publicações. As secundárias seriam os recursos que reúnem e organizam as informações primárias, como bases de dados, índices e diretórios. As terciárias, por sua vez, agregam valor a partir do uso das duas categorias mencionadas anteriormente, facilitando a localização e o acesso a tais informações. "Elas representam o ponto de partida para as ações da coleta" (ALBRECHT \& OHIRA, 2000, p. 140).

São várias as áreas que utilizam guias de fontes para suas atividades de pesquisa, tais como a História, a Biblioteconomia, dentre outras especificidades do conhecimento. A Arquivologia, por exemplo, se vale de bases de dados públicas ou guias de fontes proprietárias para realizar suas pesquisas. Um exemplo é o guia de fontes histórico elaborado por Silva (2011), cujo foco era o sistema prisional do Rio de Janeiro entre 1830 e 1890.

Nem sempre os guias de fontes são interativos, com interface de softwares. Há diversos exemplos nos quais os guias são arquivos fechados em formatos impressos ou e-books, a exemplo do Guia de Fontes Primárias do Observatório de Museus e Centros Culturais da Fiocruz (PEREIRA \& KÖPTCKE, 2008).

Os jornalistas, por sua vez, utilizam diversas fontes em suas atividades profissionais. A seleção da origem, da natureza e das características das fontes será determinada pelo tipo de pauta que se pretende apurar, o suporte no qual a notícia será veiculada, o gênero jornalístico em relação ao qual o material será elaborado e outros fatores que podem estar externos a estes critérios. Pinto (2009) define as fontes de acordo com sua natureza: elas podem ser humanas, documentais ou estatísticas. No que diz respeito às fontes humanas, a autora define quatro tipos principais. São elas: técnicos e especialistas; informantes; personagens da notícia e analistas não diretamente envolvidos com o fato. Traquina (2005), por sua vez, afirma que as fontes humanas são classificadas pelos jornalistas a partir de seus interesses ao comentar uma pauta. Estes interesses estão associados à autoridade, produtividade ou credibilidade. Estas seriam, em tese, a contrapartida para que uma fonte participe da elaboração de um conteúdo jornalístico.

Um Guia de Fontes, neste sentido, providencia aos jornalistas e repórteres o contato de fontes que sirvam principalmente como especialistas, uma vez que têm 
conhecimento específico sobre determinado assunto e fornecem dados de maneira identificada, ou ainda como analistas externos. Estes últimos participam como fontes "em off" (PINTO, 2009), podendo orientar o repórter na produção de uma pauta, mas sem necessariamente aparecer identificada como fonte que forneceu dados ou entrevistas.

Pinto (2009) sugere que os jornalistas construam um banco de dados das fontes mais recorrentes de seu trabalho, a fim de facilitar um eventual contato que deve ser feito com a agilidade que as pautas podem exigir.

Quando se trata da aproximação entre produção científica e Jornalismo para o público amplo, Nascimento e Sommer (2005) apontam que há dificuldades para o repórter em traduzir as informações das pesquisas científicas para um público-leitor que é leigo nestes temas. Muito disso se deve à dificuldade em acessar fontes científicas de informação que contribuam com o trabalho cotidiano de apuração e reportagem. Diante disso, um guia de fontes atua de maneira significativa para criar uma interface que permita aos jornalistas um acesso rápido, sistematizado e simplificado às fontes científicas mais atuais e mais indicadas para tratar diferentes temas.

Já no contexto da Computação, fontes de dados representam repositórios que podem ser acessados, agrupados, tratados e indexados visando a geração de informações relevantes aos interagentes que utilizam um determinado sistema. Desta forma, depreende-se que fontes de dados proporcionem o armazenamento, como no caso dos banco de dados, que, conforme Elmasri e Navathe (2005, p. 10) são "uma coleção de dados relacionados. Os dados são fatos que podem ser gravados e que possuem um significado implícito". Os autores exemplificam que estes dados podem ser nomes, números de telefone e endereço. Contudo, atentam que essa definição pode ser muito genérica. Ou seja, um conjunto de palavras utilizadas em um texto que estão relacionadas entre si poderia erroneamente assumir um conceito de banco de dados. Portanto, Elmasri e Navathe (2005) estabelecem algumas propriedades implícitas que tornam o uso do termo banco de dados mais restrito para a Computação. São elas: 1) representação de alguns aspectos do mundo real (mini mundo $)^{2}$; 2) coleção lógica e coerente de dados com algum significado pertinente; 3 ) projetado, construído e povoado por dados que atendam a uma proposta específica.

\footnotetext{
${ }^{2}$ Mini mundo ou Universo de Discurso (Universe of Discourse - UoD) se refere à uma coleção estruturada de dados relacionados.
} 
Elmasri e Navathe (2005) afirmam que dados organizados ao acaso, numa maneira randômica, e que não possuem grupos de usuários e interesses definidos não podem ser concebidos como banco de dados. Em síntese, "um banco de dados possui algumas fontes das quais os dados são derivados, alguns níveis de interação com os eventos do mundo real e um público efetivamente interessado em seus conteúdos" (ELMASRI \& NAVATHE, 2005, p. 10).

Albrecht e Ohira (2000) destacam que, por vezes, a literatura apresenta confusão relacionada às terminologias. Desta forma, é comum encontrar os termos banco de dados e base de dados como sinônimos. Como definição, um banco de dados reúne um conjunto de base de dados, enquanto que, uma base de dados é constituída de dados que estão inter relacionados, de maneira organizada, de modo a permitir a recuperação da informação. Portanto, "o objetivo de uma base de dados é fornecer informação atualizada (recursos estruturais), precisa e confiável (não dar a informação pela metade) e de acordo com a demanda (oferecer o que o usuário necessita)" (ALBRECHT \& OHIRA, 2000, p. 33). Por conseguinte, uma base de dados eficiente precisa armazenar e ao mesmo tempo oferecer mecanismos para que um interagente consiga encontrar exatamente o que procura.

No campo acadêmico, a fim de estudar e compreender os diversos fenômenos e saberes das variadas esferas de conhecimento, a Ciência também se vale de fontes utilizando procedimentos que se assemelham em alguma medida à apuração jornalística, porém com rigor metodológico e o escrutínio dos pares. Prova disso é que muitas pesquisas se valem, por exemplo, de análises documentais, bibliográficas e até mesmo de entrevistas para coleta de informações. Enquanto no Jornalismo, muitas vezes, o que a fonte diz já vira notícia, na Ciência existem outros crivos e filtros para que uma informação venha a compor o conhecimento científico.

As fontes para a Ciência estão em muitos lugares (SUBRAMANYAM \& SUBRAMANYAM, 1981): comunicações técnicas e científicas; sociedades científicas; jornais, revistas e periódicos; anais de conferências; dissertações, teses e pesquisas em processo; patentes; relatórios técnicos; padrões e especificações; fontes bibliográficas; dicionários; pastas e anuários; tabelas e livretos; enciclopédias; traduções; revisões de literatura; entre outros. Mas a informação também pode ser obtida com as pessoas, a partir de entrevistas, grupos focais e outras experiências controladas com seres humanos. Para Rodrigues e Blattmann (2014), o uso das fontes adequadas associadas a uma assertiva gestão da informação são indispensáveis para a geração do 
conhecimento de maneira eficiente e com menores riscos. A própria produção científica tem utilizado fontes de informação sistematizadas na forma de guias de fontes. Dois exemplos são a Universidade Federal de Minas Gerais (UFMG), que conta com a plataforma Somos ${ }^{3}$, a qual permite uma busca sobre seus pesquisadores, suas competências, suas pesquisas e sua lotação dentro da instituição. Também a plataforma Acácia ${ }^{4}$, criada por pesquisadores da Universidade Federal do $A B C$ (UFABC), tem a peculiaridade de servir como uma genealogia da produção acadêmica no Brasil, mapeando pesquisadores e seus respectivos orientadores e orientandos, fazendo também um cálculo de fecundidade e fertilidade do trabalho daquele pesquisador até o momento, estimando o quão longe foi a influência daquele acadêmico.

\section{Gestão de Conteúdos}

Um dos grandes desafios para o trabalho com dados e informações é a promoção de sua gestão de forma integrada. Isolados e sem uma representação e tratamento adequados, não são capazes de representar nada a ninguém. Neste sentido surge a Gestão de Conteúdos, área de estudos que, sob a ótica organizacional, "apóia organizações na captação, organização e distribuição de conteúdos originários de várias fontes e destinados a diversos tipos de dispositivos de saída" (PEREIRA \& BAX, 2002, p. 03).

Face ao contexto contemporâneo e aos aspectos relacionados à web e a vasta quantidade de conteúdos disponibilizados diariamente no ambiente digital, a Gestão de Conteúdos permite estabelecer requisitos mínimos que ofereçam uma solução personalizada para as organizações. Assim, a Gestão de Conteúdos trata-se de "uma abordagem tecnológica que surge em função da explosão de conteúdos multimídia na web e em intranets e visa permitir a gerência de todas as etapas, desde a criação até a publicação de conteúdos" (PEREIRA \& BAX, 2002, p. 10). Diante desta perspectiva, no que se refere ao conteúdo, este é caracterizado pelos textos, imagens, vídeos, áudios, gráficos entre outros documentos como planilhas etc.

Tendo em vista que a Gestão de Conteúdos ganha notabilidade a partir da complexidade no ambiente web - no qual a variedade e a quantidade de conteúdos disponíveis se tornam desafios para o gerenciamento -, do mesmo modo, os sistemas de gestão de conteúdo (CMS, da sigla em inglês, Content Management System) são

\footnotetext{
${ }^{3}$ http://somos.ufmg.br.

${ }^{4}$ http://plataforma-acacia.org.
} 
importantes. Segundo Boiko (2005, p. 79, tradução livre), "um CMS pode fazer muito mais do que produzir um site. Ele pode abranger qualquer parte de seu sistema de criação e organização de conteúdo que você desejar"

A implantação de um CMS em uma organização necessita de flexibilidade e de um sistema de utilização simples que facilite o compartilhamento de conteúdo. "Quando se fala em conteúdos, informação e conhecimento, cada organização é única e exige adequação própria à sua realidade" (PEREIRA \& BAX, 2002, p. 06). Isto implica em afirmar que, em termos de gestão de conteúdo, não há uma solução única e universal que atenda às especificidades das organizações (PEREIRA \& BAX, 2002). Além disso, para o desenvolvimento "é preferível que uma solução de gestão de conteúdo forneça os 'tijolos' o mais atômicos possível para o nível de abstração requerido" (PEREIRA \& BAX, 2002, p. 06, grifo dos autores). Desta forma, quem projeta o sistema pode atuar com flexibilidade na montagem chegando à solução mais adequada ao perfil da organização.

Nesse contexto de Gestão de Conteúdos, muitas organizações possuem uma visão simplista acerca do tema e possivelmente apenas procuram respostas ou melhores práticas para gerenciar enquanto continuam realizando seu trabalho (BOIKO, 2005). Para o autor, a raiz do problema está na falta de uma melhor compreensão das diferenças entre dados e conteúdo. Por vezes, há uma concepção de que conteúdo é tão simples como um dado.

O dado, neste caso, pode ser definido como uma unidade, uma matéria em estado bruto que por si só não agrega valor. Ele é compreendido também como uma base para a construção da informação. Sobre esta concepção, Boiko (2005) define que "os dados consistem em pequenos fragmentos de informações de computador números, palavras, imagens, sons - que têm muito do significado humano extraído deles" (BOIKO, 2005, p. 04, tradução livre). Nesta circunstância digital, o fato de termos muitos dados neste formato não implica que outros registros não sejam dados (DAMA, 2017). Desta forma, "como hoje podemos capturar tantas informações eletronicamente, chamamos muitas coisas de 'dados' que não teriam sido chamadas de 'dados' em tempos anteriores - coisas como nomes, endereços, datas de nascimento" (DAMA, 2017, p.47, tradução livre).

A relação entre dado e informação já foi bastante discutida na literatura colocando estes termos como indissociáveis, uma vez que são vitais no dia-a-dia das organizações. Portanto, os dados são chamados de matéria-prima da informação e as 
informações são chamadas de dados no contexto (DAMA, 2017). Para autores como Boiko (2005), a informação é concebida a partir da capacidade humana de atribuir significado aos dados. Na mesma linha, Choo (2003) defende características mais intrínsecas dos indivíduos em relação à informação, e que esta, assim como os insights, surge na mente. Para o autor, "a busca e o uso da informação são um processo dinâmico e socialmente desordenado que se desdobra em camadas de contingências cognitivas, emocionais e situacionais" (CHOO, 2003, p. 62). Em síntese, o dado é aquilo que se obtém e a informação ganha contexto a partir de uma subjetividade humana. A partir daí, segundo Boiko (2005), o conteúdo é definido pela soma de dados e informação.

Feitas estas diferenciações, o conteúdo científico, portanto, será caracterizado pela utilização de dados de natureza científica - sendo estes números, palavras, imagens ou sons - aliado a informações de abordagem quantitativa e/ou qualitativa, com rigor metodológico e uma narrativa que faz parte do trabalho desenvolvido por pesquisadores e cientistas.

Sob a perspectiva da gestão, a informação é elemento crucial, especialmente no auxílio ao conhecimento e nas tomadas de decisões dentro das organizações. Concebida em uma instância cognitiva, a informação será selecionada, identificada e organizada pelo sujeito numa forma de classificação. O resultado desse processo é denominado de representação.

Por um ponto de vista cultural, antropológico e, também, semiótico, a representação abrange objetos e conceitos na mente humana. "O processamento destas representações antes de agir praticamente no mundo, de acordo com o resultado deste processamento, é uma das características mais fundamentais da humanidade" (MARCONDES, 2001, p. 63). Destaca-se que o processo da busca por informação por parte do indivíduo ocorre de maneira hierárquica, desde uma necessidade por informações gerais, às interações com fontes e sistemas de recuperação de informação até o uso final das informações obtidas (MARCONDES, 2001).

A $\mathrm{Cl}$ define a representação associada à classificação e à recuperação da informação. Classificação esta que contempla indexação, taxonomias, árvores semânticas e a gestão do conhecimento. As pesquisas nesta área discutem a representação com base na problemática contemporânea acerca do volume informacional e na variedade de dispositivos à disposição para o acesso e busca da 
informação. Avanços Computação, por sua vez, permitem uma diversidade de propostas, linguagens e metadados para fins de catalogação, classificação e também indexação das informações. "Juntamente com tags HTML especiais, as tags META, metadados constituem uma possível solução para a explosão informacional trazida pela Internet" (MARCONDES, 2001, p. 62).

No cenário organizacional, o controle e a gestão do volume de informações é um desafio contínuo. Uma vez que a informação é compreendida como um recurso valioso para a tomada de decisão, sendo inclusive, fundamental para manter a organização competitiva, quanto mais se planeja, mais informação é necessária (TEIXEIRA \& VALENTIM, 2017). Nesta perspectiva, a representação tem papel fundamental para a economia da informação. "Na economia da informação/conhecimento, a representação deve ser tão rica cognitivamente de modo a permitir a um usuário inferir o conteúdo do documento" (MARCONDES, 2001, p. 67). É neste ponto que a representação é importante, visto que serve para economizar energia no processo de busca por informação. Segundo Marcondes (2001), na leitura de um documento, por exemplo, é mais econômico ler o resumo que o texto por completo.

Tendo em vista as necessidades do usuário e das organizações, as mudanças significativas no acesso e na busca por informação, como a possibilidade de armazenamento digital de grande volume de dados, linguagens de indexação, a pesquisa de palavras-chave por meio dos motores de busca em texto e voz, o uso de URLs, diferentes mídias e suportes, conexões e velocidade também desafiam os sistemas de recuperação da informação. São necessários sistemas ágeis e ao mesmo tempo confiáveis. "Desse modo, o processo de recuperação da informação necessita de recursos eficientes para propiciar informações relevantes" (TEIXEIRA \& VALENTIM, 2017, p. 83-4). Neste sentido, os sistemas de informação atuam como intermediários entre as necessidades do acesso e da busca por informação e a representação dos conteúdos. Eles são considerados, ainda, instrumentos linguísticos de comunicação.

Mas, o que fazer se os dados estão representados e disponíveis em bancos de dados e sistemas distintos? É neste contexto que surge a ideia de interoperabilidade, compreendida na capacidade de um sistema se comunicar com outro. Para a área da Tecnologia da Informação, o conceito é compreendido, em linhas gerais, como a capacidade de troca de informações entre computadores e programas de fabricantes distintos. Diferente de integração, que se refere ao processo de conexão, a interoperabilidade permite que dois ou mais sistemas trabalhem em conjunto num 
sentido comunicacional na troca de dados. A definição da Organização Nacional de Padrões de Informação (NISO, do Inglês National Information Standards Organization) estabelece que a interoperabilidade é a "capacidade de sistemas diversos, com diferentes hardwares e plataformas de softwares, estruturas de dados e interfaces, trocarem dados com a mínima perda de conteúdo e funcionalidade" (NISO, 2004, não p., tradução livre). De acordo com Santarém Segundo et al. (2019), a interoperabilidade significa também a capacidade de troca de dados e informações entre diferentes organizações independentemente dos sistemas ou plataformas que utilizem. Sob o ponto de vista da Computação, "a interoperabilidade apresenta-se com muitas variáveis e requisitos, que vão desde a estrutura de arquivo a ser trocado até os modelos funcionais de acesso computacional" (SANTARÉM SEGUNDO et al., 2019, p. 75).

Diante de um cenário como o da Internet, em que há elevado volume de informações, complexidade, estruturas e fluxo, a interoperabilidade é importante. "De nada adianta a informação existir, se quem dela necessita não sabe da sua existência ou se ela não puder ser encontrada" (SAYÃO \& MARCONDES, 2001, p. 26). Neste contexto também emerge a ideia de transparência dos Sistemas de Informação. Em termos conceituais, "transparência é definida como a ocultação do usuário e do programador do aplicativo da separação dos componentes em um sistema distribuído" (COULOURIS et al., 2012, p. 23, tradução livre). Implica que o sistema deverá ser percebido como um todo e que do ponto de vista do usuário não interessa saber sobre componentes, mas sim, o resultado final que esse sistema pode oferecer.

Na área de Engenharia de Software, Cysneiros (2013) explica que existem inúmeras definições acerca de um sistema transparente, mas o ponto principal da transparência é o de divulgação de informações. "Acreditamos que para que o software seja transparente as informações com que ele trata devem ser transparentes (Transparência da Informação)" (CYSNEIROS, 2013, p. 19, tradução livre). Desta forma, a transparência e a interoperabilidade são essenciais para que um sistema de informação seja eficiente.

\section{Desenvolvimento de Software}

O Guia de Fontes @UFPR foi desenvolvido com objetivo de dar acesso à Imprensa e à sociedade em geral a informações sobre as especialidades de pesquisadores brasileiros. Com a ferramenta, além de facilitar o trabalho jornalístico e 
promover a produção de conteúdo de qualidade, pretende-se a divulgação científica e a transparência acadêmica.

A solução está sendo desenvolvida como um software livre e a partir de tecnologias livres ou open source, o que significa que existem dependências que obrigam que seu código-fonte seja igualmente compartilhado com a mesma lógica. Ao fazer isso, a Agência Escola prospecta e desenvolve uma ferramenta que espera que possa ser compartilhada com outras instituições de Ensino Superior, na lógica de contribuir para comunicação pública e divulgação científica.

Do ponto de vista de desenvolvimento, há vários aspectos das Ciências da Computação envolvidas na criação e manutenção de um software. Neste sentido, a Engenharia de Software abrange "um processo, um conjunto de métodos (práticas) e um leque de ferramentas que possibilitam aos profissionais desenvolverem software de altíssima qualidade" (PRESSMAN \& MAXIN, 2016, p. 14). No entanto, para este artigo, por motivos de conveniência, optou-se por discutir um dos principais tópicos da gerência de projeto, a Análise de Requisitos, além da perspectiva de metodologias e métodos e tecnologias adotados.

O projeto do Guia de Fontes @UFPR contou com uma análise de requisitos pautada especialmente nas demandas da Superintendência de Comunicação e da $\mathrm{AE}$ da UFPR, que no passado tiveram iniciativas similares, com o mesmo intuito de prover informação sobre especialidades e especialistas da Universidade para Imprensa. No entanto, nesta análise verifica-se que as soluções ou estiveram centradas na construção de bases de dados locais ou em outras iniciativas "caseiras" do próprio time de assessores de Imprensa, focadas na utilização de softwares populares de planilha de dados, a exemplo do Microsoft Excel.

A partir da observação e de diálogos com as equipes, foram estabelecidos os requisitos funcionais do projeto, centrados em três perfis de interagentes, conforme descrito a seguir:

- Jornalistas: busca de palavras-chave sobre temas de pesquisa; busca de nomes de pesquisadores; visualização de dados para contato com pesquisadores (telefone, e-mail); visualização de resumo do currículo de pesquisadores; visualização de data de atualização dos dados; acesso ao currículo lattes completo de pesquisadores. 
- Assessores de comunicação: login no sistema, com usuário e senha; recuperação de senha; cadastro de usuários; listar usuários; listar pesquisadores; adicionar/alterar contatos de pesquisadores; definição de contatos como públicos ou privados; gerenciamento (adicionar ou remover) de palavras-chave do currículo de pesquisadores; envio de senha temporária para pesquisadores; sincronização e atualização de dados dos pesquisadores com o Currículo Lattes.

- Pesquisadores: login no sistema, com usuário e senha; recuperação de senha; adicionar/alterar seus contatos; definição de contatos como públicos ou privados; gerenciamento (adicionar ou remover) de palavras-chave de seu currículo; sincronização e atualização de dados do Currículo Lattes.

Os requisitos não funcionais, por sua vez, estão relacionados, no projeto do Guia de Fontes @UFPR, à interoperabilidade com o Lattes Institucional; sincronização de dados programada e sob demanda; indexação de base de dados para prover velocidade nas transações e resposta ao usuário; usabilidade, dispensável treinamento, tutorial ou manual para operação do sistema; acessibilidade; uso de tecnologias livres e/ou open source no processo de desenvolvimento; e código aberto para outras IES brasileiras.

O desenvolvimento propriamente dito esteve centrado na filosofia ágil, que na Computação é compreendida com a "satisfação do cliente e a entrega incremental antecipada; equipes de projeto pequenas e altamente motivadas; métodos informais; artefatos de engenharia de software mínimos; e, acima de tudo, simplicidade no desenvolvimento geral" (PRESSMAN \& MAXIN, 2016, p. 66). Além disso, do ponto de vista de princípios, "priorizam a entrega mais do que a análise e o projeto (embora essas atividades não sejam desencorajadas); também priorizam a comunicação ativa e contínua entre desenvolvedores e clientes" (PRESSMAN \& MAXIN, 2016, p. 66).

Neste processo, privilegiando a aceleração da comunicação e a colaboração entre todos os participantes, foi adotado o Scrum, um método de desenvolvimento ágil de software usado "para orientar as atividades de desenvolvimento dentro de um processo que incorpora as seguintes atividades metodológicas: requisitos, análise, projeto, evolução e entrega" (PRESSMAN \& MAXIN, 2016, p. 78). Neste sentido, importante destacar três conjuntos das atividades de desenvolvimento: backlog (prioridades de requisitos e funcionalidades do projeto), Sprints (unidade de trabalho, medida no tempo ajustado para cumprimento das metas estabelecidas no projeto), 
reuniões Scrum (encontros breves, com atualização do andamento do trabalho de cada membro da equipe) e Demos (entrega incremental de funcionalidades implementadas para avaliação do cliente).

Destacam-se, também, alguns aspectos da Arquitetura da Informação do Guia de Fontes @UFPR, importantes para compreender como a interface foi pensada. Compreende-se esta arquitetura a partir dos conhecimentos direcionados ao tratamento dos "aspectos informacionais, estruturais, navegacionais, funcionais e visuais de ambientes informacionais digitais por meio de um conjunto de procedimentos metodológicos a fim de auxiliar no desenvolvimento e no aumento da usabilidade" (CAMARGO \& VIDOTTI, 2011, p. 24).

No sentido da organização e rotulação do sistema, é importante observar o mecanismo de busca, que ocupa destaque na interface do Guia, dada a natureza do software e a sua centralidade para navegação no sistema; bem como a organização de itens de menu secundários, centrados ou no usuário ou no conteúdo.

Centrado no usuário, o Guia foi desenvolvido com um menu superior que dá acesso a conteúdo informativo para cada perfil de usuário (Jornalista, Assessor de Comunicação e Pesquisador). Além disso, o login permite que haja também uma visão com funcionalidades específicas tanto para os assessores como para os pesquisadores, garantindo que cada qual possa ter acesso rápido e fácil para informações voltadas diretamente para o que o Guia provê para cada perfil.

Centrado no conteúdo, foi desenvolvido um menu, também no topo do site, com rótulos pautados nos nomes das grandes áreas da Ciência (Ciências Exatas e da Terra; Biológicas; Engenharias; Saúde; Agrárias; Sociais Aplicadas; Humanas; Linguística, Letras e Artes) e que funcionam como editorias, que dão acesso aos últimos artigos publicados pelos pesquisadores da Instituição. Neste caso, utilizou-se da Tabela de Áreas do Conhecimento da CAPES, uma taxonomia corporativa que "apresenta uma hierarquização em quatro níveis, do mais geral ao mais específico, abrangendo nove grandes áreas nas quais se distribuem as 48 áreas de avaliação" (CAPES, 2017).

Figura 1 Tela do Guia de Fontes@UFPR onde se pode notar a composição da marca e a estrutura de menus. 


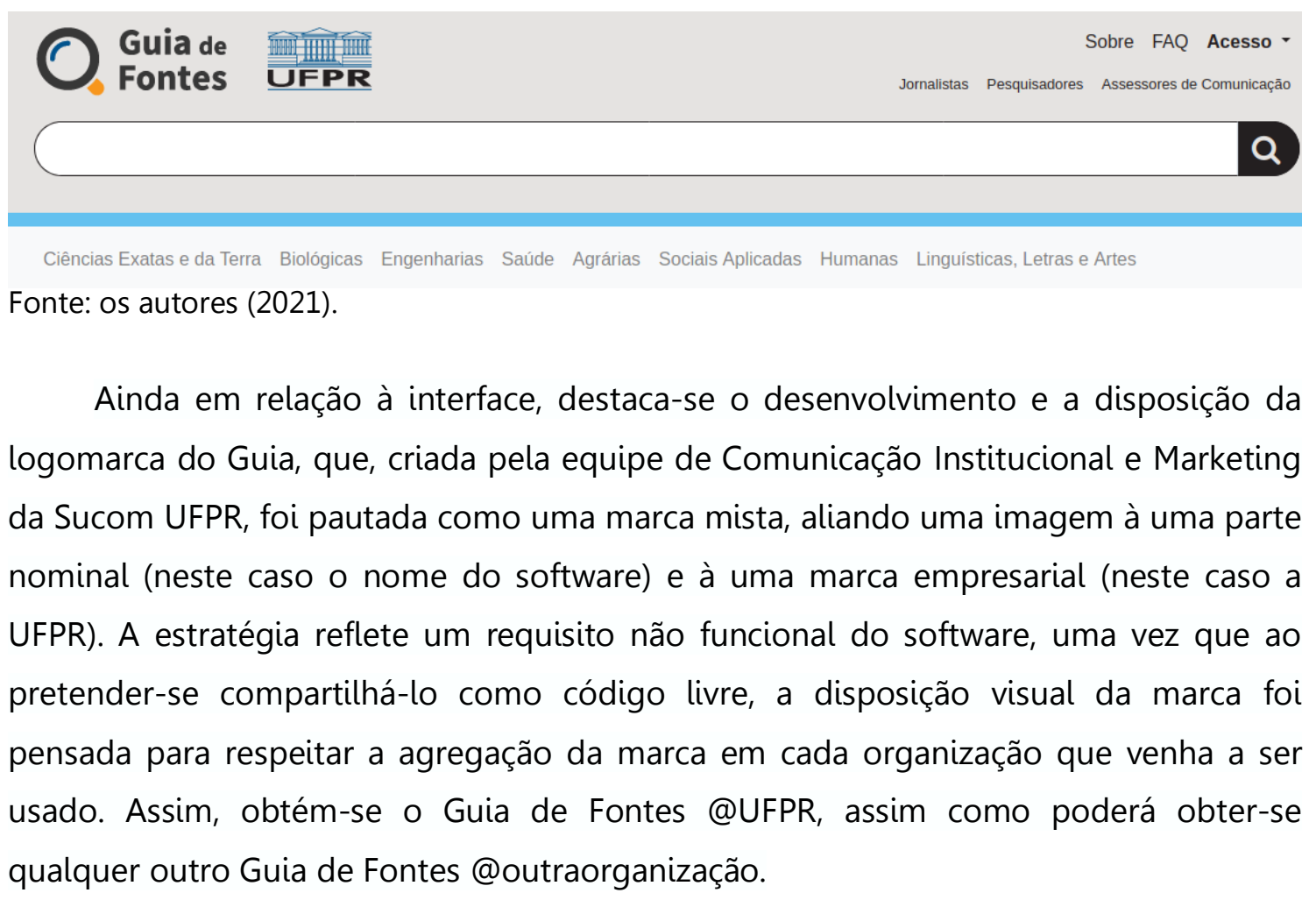

e da Terra Biológicas Engenharias Saúde Agrárias Sociais Aplicadas Humanas Linguísticas, Letras e Artes Fonte: os autores (2021).

Ainda em relação à interface, destaca-se o desenvolvimento e a disposição da logomarca do Guia, que, criada pela equipe de Comunicação Institucional e Marketing nominal (neste caso o nome do software) e à uma marca empresarial (neste caso a UFPR). A estratégia reflete um requisito não funcional do software, uma vez que ao pretender-se compartilhá-lo como código livre, a disposição visual da marca foi pensada para respeitar a agregação da marca em cada organização que venha a ser qualquer outro Guia de Fontes @outraorganização.

Figura 2 Interface com a visão interna, após login, de um pesquisador no Guia de Fontes @UFPR 


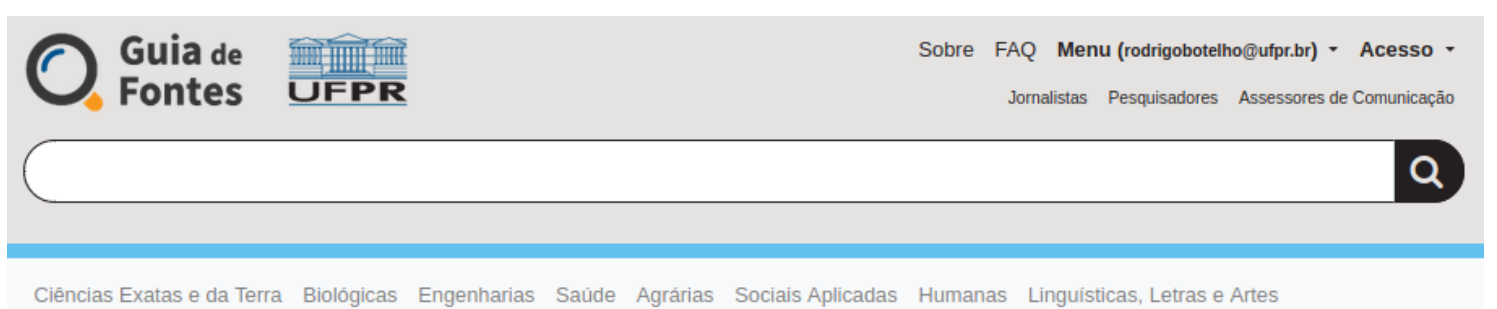

Ciências Exatas e da Terra Biológicas Engenharias Saúde Agrárias Sociais Aplicadas Humanas Linguisticas, Letras e Artes

\section{Rodrigo Eduardo Botelho Francisco}

COORDENADOR(A) DE CURSO DE POS-GRADUACAO (PROGRAMA DE POS-GRADUACAO EM GESTAO DA INFORMACAO) - SA -

Setor de Ciências Sociais Aplicadas - Departamento de Ciência e Gestāo da Informaçāo

Contatos: Adicionar/alterar Contatos

Email: rodrigobotelho@ufpr.br (público) / nounnum Dirion (privado)

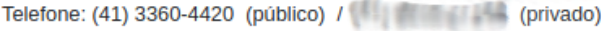

Apresentaçāo do pesquisador (resumo)

Pesquisador vinculado aos programas de pós-graduaçāo em Comunicaçāo e em Gestão da Informaçāo; e docente do Departamento de Ciência e Gestão da Informação da Universidade Federal do Paraná UFPR. Coordenador do Programa de Pós-Graduaçāo em Gestâo da Informaçāo da UFPR para o período 2020-2021. Doutor e mestre em Ciências da Comunicação pela Escola de Comunicaçāo e Artes da USP com pós-doutorado na Universidad Complutense de Madrid e na Universitat Autònoma de Barcelona. É especialista em Computaçāo - na área de Desenvolvimento de Software para Web - e em Gestāo Pública pela UFSCar; e bacharel em Comunicaçāo Social - Habilitaçāo em Jornalismo - pela Unesp. Pesquisador na Rede de Pesquisa Aplicada Jornalismo e Tecnologias Digitais, vinculada à Sociedade Brasileira de Pesquisadores em Jornalismo, SBPJor; e no Núcleo de Apoio à Pesquisa (NAP) Escola do Futuro, da USP. É criador do Sistema de Apoio à Comunicação Integrada (SACl), um software livre de gestão convergente e colaborativa de produçāo midiática registrado junto ao INPI. Atua nas áreas de Comunicaçāo Organizacional, Jornalismo Digital, Jornalismo Especializado, Computaçāo e Novas Tecnologias, com ênfase em temas como tecnologia de informaçāo e comunicaçāo, interatividade, Internet, desenvolvimento de software, software livre, Jornalismo Digital, inclusāo digital e literacias digitais.

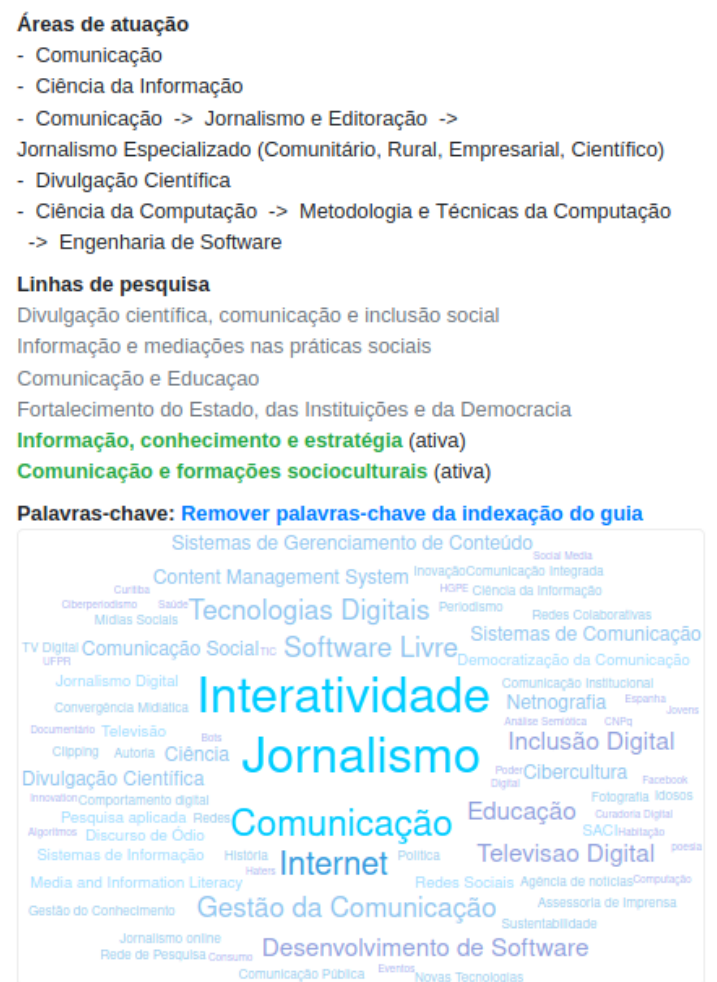

Apoio
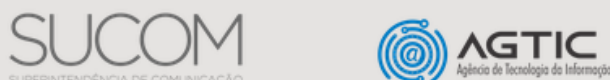

Guia de Fontes - Copyrighto 2020 - Universidade Federal do Paraná - UFPR

Fonte: os autores (2021).

Os dados do Guia provêm de bases institucionais da UFPR e do Lattes institucional, um conjunto de dados sobre a Universidade advindo do Currículo Lattes do CNPq, especificamente áreas do conhecimento, linhas de pesquisa, texto informado pelo próprio pesquisador e frequência de um conjunto de palavras-chave associadas à produção científica e técnica cadastrada no Currículo. Por ter relação indireta com a expertise do pesquisador, são excluídas da busca as palavras-chave provindas de 
bancas julgadoras, editoração, organização de eventos, orientações, participação em eventos e traduções.

Somente dados de servidores docentes da ativa e aposentados estão disponíveis no Guia de Fontes. Sobre eles, assim como o Currículo Lattes, o Guia disponibiliza apenas informações públicas, informadas à plataforma pelo próprio pesquisador no momento em que ele preenche seu currículo. Neste sentido, elas são de sua total responsabilidade.

Esta integração é um dos principais diferenciais do Guia, uma vez que garante interoperabilidade para reuso de dados, automação e atualização contínua, além de transparência no processo de construção do Banco de Dados. Com isto, evita-se que tanto os pesquisadores como assessores de comunicação tenham que inserir dados manualmente no Guia de Fontes, replicando um esforço intelectual que já existe na atualização do Currículo Lattes, uma base de dados científica reconhecida nacionalmente e com ampla utilização no cenário acadêmico brasileiro.

Em termos de programação, o Guia de Fontes @UFPR foi desenvolvido com Java e MySQL, ambos em sua versão oito. O primeiro trata-se de linguagem de programação orientada a objetos criada na década de 90 pela Sun Microsystems, desde 2009 é mantida pela Oracle Corporation. O segundo é um Sistema Gerenciador de Banco de Dados (SGBD) criado na década de 90, amplamente utilizado na Internet como repositório de dados de sites e sistemas de informação, desde 2009 é também mantido pela Oracle Corporation.

A escolha do MySQL como base principal de dados se deu em virtude do mesmo ser um SGBD amplamente utilizado na web e ser de utilização livre, ou seja, não há necessidade de custos com licença. Além disso, se trata de um banco de dados largamente utilizado na UFPR.

A utilização do MySQL como uma única base de dados para prover os serviços do Guia de Fontes, no entanto, envolveu a integração de bases de dados heterogêneas facilitada pela interoperabilidade entre sistemas, conforme pode ser observado na Figura 3. A base principal do Guia, denominada metabase, foi construída a partir das seguintes fontes de dados:

- Sistema Gerenciador de Banco de Dados Oracle (fonte de dados institucional da UFPR) - utilizado para obtenção dos dados mínimos (nome, CPF e e-mail) de docentes da Instituição; 
- Lattes PRPPG15 - serviço remoto que permite a obtenção do identificador do pesquisador no CNPq, utilizando o CPF como parâmetro;

- Lattes PRPPG2 - serviço remoto que permite a obtenção do currículo Lattes em formato $\mathrm{XML}^{6}$, utilizando o identificador do pesquisador como parâmetro;

- Páginas de Periódicos e Revistas científicas (onde estão publicados os artigos) busca das meta informações das páginas (Dublin Core e Open Graph ${ }^{7}$ ) com objetivo de obter o resumo de cada artigo, por meio da utilização dos campos $\mathrm{DOI}^{9}$ e Home Page de cada publicação para localizar as páginas dos periódicos.

Figura 3 Arquitetura do Guia de Fontes @UFPR

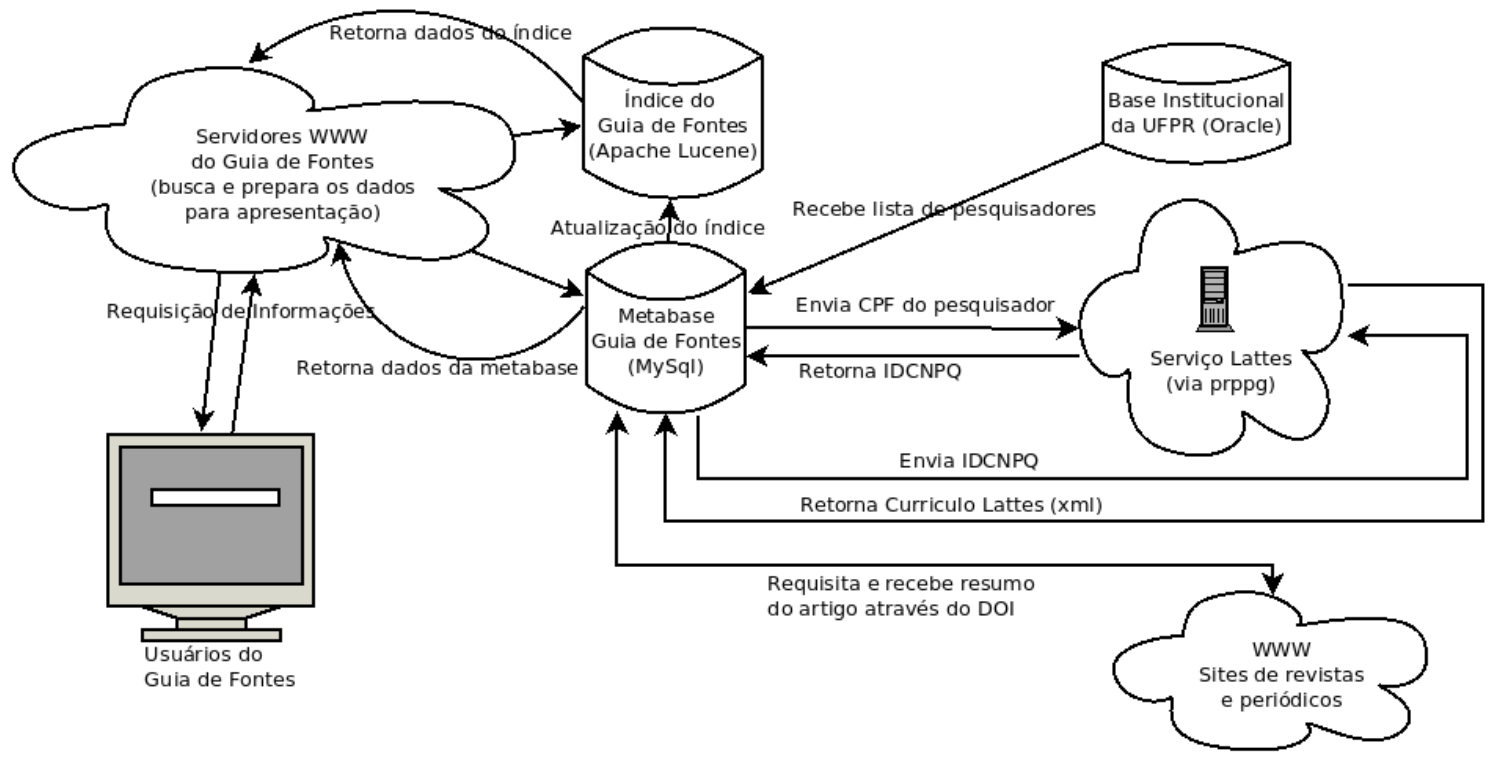

Fonte: os autores (2021).

Metabase, no projeto, pode ser entendida como o resultado da integração de várias fontes de dados condensadas e dispostas convenientemente em uma única base. Esta, por sua vez, poderá ser indexada e otimizada para que possibilite a extração de informações relevantes para a finalidade a que se destina.

\footnotetext{
${ }^{5}$ PRPPG é a sigla para Pró-Reitoria de Pesquisa e Pós-Graduação da UFPR, que neste caso é a mantenedora dos serviços do Lattes Institucional.

${ }^{6}$ XML vem da sigla de Extensible Markup Language, uma linguagem de marcação recomendada pela World Wide Web Consortium (W3C) para descrição de diversos tipos de dados, com o principal objetivo de facilitar o compartilhamento de informações na Internet.

7 Dublin Core é um conjunto de metadados padronizados utilizado para descrever recursos na web, tais como vídeos, imagens, textos etc.

${ }^{8}$ Open Graph é um protocolo que define um conjunto de metadados para facilitar o compartilhamento de recursos (vídeos, imagens, textos etc) nas mídias sociais, tais como Facebook, Instagram, Twitter etc.

${ }^{9}$ Digital Object Identifier (DOI) é um identificador único registrado em http://doi.org.br. O serviço, um ponteiro que permite que cada documento (livro, artigo ou outro tipo de publicação) seja único no meio digital, é mantido pela International DOI Foundation (IDF).
} 
A integração ocorre de maneira assíncrona, sendo atualizada periodicamente em intervalos de oito dias para os dados dos currículos e sob demanda para os resumos das publicações. Isto quer dizer que, quando as publicações no Guia de Fontes são acessadas, os resumos são buscados de maneira assíncrona e armazenados para futuras buscas.

Depois de construída, a metabase é submetida a uma rotina de indexação com base nos seguintes critérios: nome do pesquisador; resumo do currículo; palavraschaves aglutinadas - todas as palavras-chaves utilizadas no currículo do pesquisador; linhas de pesquisa; e área de atuação; além de dados das publicações, como título, palavras-chave, áreas de conhecimento, resumo etc. Estes dados são indexados pelo Apache Lucene $^{10}$ e ficam disponíveis em um repositório de índice gerenciado pela própria da biblioteca de buscas do Apache Lucene.

Neste caso, a função do Apache Lucene é facilitar a indexação de banco de dados relacional em sua forma natural, ou seja, tabelas, colunas, relacionamentos etc.

Como sistema web, o Guia de Fontes é disponibilizado na web por meio do servidor de páginas Apache HTTP e Apache Tomcat, soluções desenvolvidas pela Apache Software Foundation e distribuídas como softwares livres. Estes atuam em conjunto para possibilitar a exposição do Guia de Fontes na web e são disponibilizados e mantidos na infraestrutura de serviços da UFPR.

Outras dependências do processo de desenvolvimento estão centradas em tecnologias e frameworks como o Model View Controler (MVC) Springboot em sua versão dois, assim diversas outras tecnologias que fazem parte do framework MVC; e o Hibernate Search ${ }^{11}$, que tem grande destaque no projeto como motor de busca utilizado.

Gitlab ${ }^{12}$ é o gerenciador de versão utilizado para gerenciar e armazenar o código fonte do Guia de Fontes, que fica hospedado na infraestrutura da UFPR. Sua distribuição está prevista para ocorrer sob a Licença Pública Geral GNU (GPLv3) ${ }^{13}$, que entre outras coisas prega liberdade para usar, modificar e compartilhar o código fonte.

\section{O Guia de Fontes e a Divulgação Científica}

\footnotetext{
10 https://lucene.apache.org.

${ }^{11}$ http://hibernate.org/search.

12 https://gitlab.ufpr.br.

${ }^{13}$ https://www.gnu.org/licenses/quick-guide-gplv3.html.
} 
Visto que o Guia de Fontes é concebido como uma fonte de informação científica, servindo como uma solução concreta para Imprensa e para sociedade na busca por informações desta natureza, destaca-se o viés democrático desta ação. Assim, a proposta suscita o debate e colabora para a Divulgação Científica (DC), que, por sua vez, tem como papel fundamental "democratizar o acesso ao conhecimento científico e estabelecer condições para a chamada alfabetização científica" (BUENO, 2010, p. 1).

Sobre a DC, Bueno (2010) desperta atenção para o perfil do público relacionado ao processo de circulação de informações de cunho científico. Na Divulgação Científica, este público "é, prioritariamente, um não iniciado, quer dizer, não tem, obrigatoriamente, formação técnico-científica que the permita, sem maior esforço, decodificar um jargão técnico" (BUENO, 2010, p. 2). Assim, a DC veicula informações de maneira que estas sejam acessíveis, em termos de linguagem, ao público leigo.

Figura 4 Apresentação de resultado para busca de palavra-chave no Guia de Fontes @UFPR

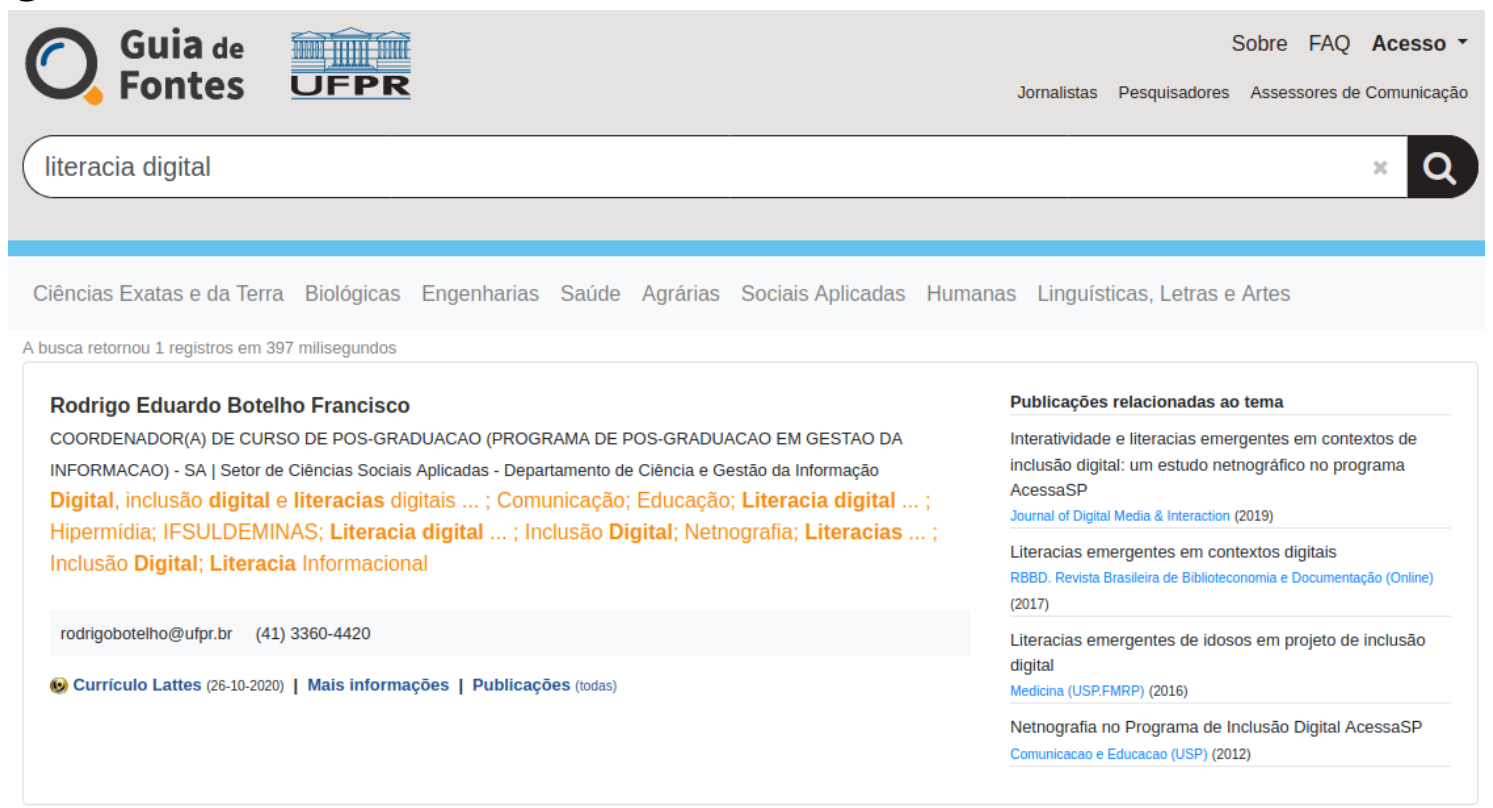

Fonte: os autores (2021).

Num contraponto, pela perspectiva do público em relação à percepção sobre Ciência e Tecnologia no Brasil, uma pesquisa realizada por Delabio et al. (2021) revela que a maioria dos entrevistados acredita que Ciência e Tecnologia trazem mais benefícios que malefícios à humanidade. Contudo, os autores destacam contrastes evidenciados no estudo como, por exemplo, o pouco interesse por parte do público 
sobre o tema e na participação em decisões relacionadas aos rumos da Ciência, além de uma crença de que parte das pessoas é incapaz de aprender Ciência. Ademais, mesmo acreditando em benefícios, não sabem apontar quais (DELABIO et al., 2021). Desta forma, a importância da Divulgação Científica é reforçada por um papel social também enquanto Comunicação Pública que tem perspectiva cidadã e contempla temas de interesse coletivo (DUARTE, 2007).

Já buscando compreender a visão dos cientistas brasileiros, um estudo conduzido por Massarani e Peters (2016) mapeou como eles observam a mídia e o relacionamento com os jornalistas. Em linhas gerais, os resultados do trabalho mostraram que há uma concordância entre os cientistas em que a comunicação de suas pesquisas precisa ser adaptada visto às especificidades da Ciência e jargões técnicos. "As respostas sugerem que os cientistas aceitam, em algum nível, que eles devem adaptar sua maneira de falar para os jornalistas, mas apenas até certo ponto" (MASSARANI \& PETERS, 2016, p. 1170-1, tradução livre). Assim, os cientistas acreditam que uma linguagem mais descontraída deve ficar à cargo dos repórteres, compreendendo que essa pode ser uma estratégia para a Imprensa na manutenção da atenção do público.

Outro ponto importante referente ao estudo realizado por Massarani e Peters (2016) diz respeito sobre a disponibilização das publicações científicas aos jornalistas. De acordo com os autores, os cientistas entrevistados relataram que na última década tiveram fácil acesso aos artigos em periódicos internacionais por meio do Portal da Capes. "Mas, não é o caso dos jornalistas" (MASSARANI \& PETERS, 2016, p. 1172, tradução livre). Neste sentido, destaca-se que embora existam algumas iniciativas no âmbito brasileiro como o Scielo ${ }^{14}$, a demora na disponibilização de novos números por parte dos periódicos se configura em "um obstáculo considerável para os jornalistas que necessitam de informações atualizadas devido à natureza da produção jornalística" (MASSARANI \& PETERS, 2016, p. 1172, tradução livre).

Para além das dificuldades acerca da Divulgação Científica como a perspectiva do público, o relacionamento entre cientistas e jornalistas e a disponibilidade das publicações científicas, as rotinas jornalísticas como apuração, contato com a fonte, checagem, fluxos de revisão e edição também devem ser consideradas. Acrescenta-se a isso, a voz independente, resultado após todos os processos do trabalho jornalístico. Também como apontado por Massarani e Peters (2016), há um entendimento por

\footnotetext{
14 http://scielo.br.
} 
partes dos cientistas que o jornalista deve consultá-los antes de publicar uma matéria a fim de evitar erros. Contudo, como destacado pelos autores, essa é uma ideia fortemente rejeitada pelos jornalistas. Neste sentido, jornalistas compreendem que seu papel é o de mediador das informações entre as coisas do mundo e a sociedade. Diante da cultura profissional jornalística não seria pertinente a revisão de uma matéria por parte do entrevistado/especialista/cientista em virtude das especificidades técnicas do assunto ou tema. Porém, Bueno (2010), por sua vez, aponta para uma possível espetacularização da notícia, especialmente quando o jornalista não está apto a decodificar o discurso especializado.

Estes, assim como todos os aspectos sobre acesso e busca por informações científicas em conjunto com a comunicação sobre Ciência - importantes para a constituição da Divulgação Científica -, tornam um Guia de Fontes pertinente na medida em que ele é uma ferramenta que pode aproximar cientistas, jornalistas e a sociedade em geral. Sobretudo, enquanto Fonte de Informação, um guia desta natureza pode ser assumido frente à concepção de Recursos de Conhecimento (RC) (CASSOTTA et al., 2017), que são definidos como meios ou ferramentas que tem por finalidade armazenar, compartilhar e promover a reutilização do conhecimento científico. Nesse sentido, o intuito maior de um RC "é a integração e/ou relacionamento entre autores, pesquisadores, professores e estudantes para o trato de informação de interesse em comum" (CASSOTTA et al., 2017, p.19).

A falta de mecanismos ágeis que facilitem a busca organizada e o diálogo entre jornalistas e fontes científicas comprometem os esforços da Comunicação Pública e da Divulgação Científica. Frente a este desafio, o Guia de Fontes @UFPR favorece uma aproximação entre cientistas e jornalistas, sendo um meio ou uma ferramenta capaz de contribuir para as rotinas jornalísticas - desde a apuração e contato com as fontes - ao mesmo passo que colabora para o acesso e busca de conteúdo científico, seja por parte dos especialistas ou da sociedade em geral.

\section{Considerações Finais}

O presente artigo teve como objetivo apresentar um relato sobre $\mathrm{O}$ desenvolvimento do Guia de Fontes @UFPR e, ainda, discutir a perspectiva da interdisciplinaridade entre as áreas que provém o conhecimento necessário para discussão sobre busca de informação científica numa perspectiva de pesquisa aplicada. 
Enquanto Fonte de Informação, o Guia pode ser compreendido a partir das diferentes perspectivas, tanto como um Banco de Dados, como a partir da ideia de fonte de informação, assim como discutido pela $\mathrm{Cl}$ e pelo próprio Jornalismo. Do ponto de vista da gestão, é importante observar a complexidade do conteúdo científico, bem como os aspectos de representação e recuperação de informação desta natureza num contexto organizacional e dependente de tecnologias interoperáveis. Além disso, destaque para a ideia de transparência, uma vez que o interagente, ao utilizar motores de busca para localização de informações desta natureza, tem a expectativa de interação com o sistema sem a necessidade de conhecimentos especializados para sua operação.

Outro ponto de destaque acerca da representação da informação é que essa assume características intrínsecas por parte dos indivíduos. Ao acessar um sistema para fazer uma busca, há uma inferência sobre os resultados que determinam o que interessa do que não interessa. Neste sentido, a interface de resultados do Guia de Fontes @UFPR possui uma Arquitetura da Informação pautada na usabilidade, que consequentemente, reflete na economia da informação (MARCONDES, 2001).

Como resultado, o Guia de Fontes @UFPR facilita a rotina de produção de jornalistas e assessores de Imprensa no que se refere ao contato com as fontes humanas, neste caso, os pesquisadores da UFPR. A busca por palavras-chave atende a demanda com a agilidade necessária num contexto contemporâneo em relação à Internet. Sobretudo, o modo em que foi projetado o Guia auxilia tanto o trabalho da Imprensa como da sociedade em geral, uma vez que pode ser utilizado na busca por temas ou assuntos específicos que são ao mesmo tempo de interesse coletivo. Além disso, frente ao volume e a variedade de informações em diferentes periódicos que podem, por vezes, ser um obstáculo na obtenção ou levantamento das publicações, um Guia de Fontes é um meio que pode aproximar cientistas dos jornalistas.

Naturalmente, o relato do desenvolvimento do Guia neste artigo está circunscrito ao contexto e limitações do próprio formato. É sabido que as discussões sobre divulgação científica na contemporaneidade requerem um debate aprofundado, reflexivo e crítico, pautado tanto numa perspectiva de Comunicação Pública e Democratização da Ciência, assim como numa concepção de Ciência e Técnica que permita abrir a "caixa preta" da tecnologia, e apresentar tanto os princípios de sua concepção, assim como as controvérsias envolvidas no processo. Trilhar este caminho, 
no entanto, requer uma postura de pesquisa aplicada, que, acredita-se, está visível no processo de desenvolvimento e prototipação relatados.

A ideia de protótipos funcionais, por sua vez, é importante para a pesquisa aplicada porque permite trabalhar com experimentações, através da liberação gradual de pequenas porções do sistema para serem testadas, colocando conceitos a prova, revisitando-os e revisando-os constantemente, com uma participação mais efetiva dos atores envolvidos. Neste sentido, o Guia de Fontes @UFPR, a partir da metodologia de desenvolvimento adotada, possui, na data de conclusão deste artigo, um versionamento (versão 3.0.0) e um backlog que comprovam um desenvolvimento ágil, ao mesmo tempo que um cenário de trabalhos futuros, dentre eles vislumbradas novas funcionalidades de integração com sistemas de informação científica, mais funcionalidades para o trabalho jornalístico, gestão de mailing, notificações, dentre outras.

\section{Referências}

ALBRECHT, R. F., \& OHIRA, M. L. B. (2000). Bases de dados: metodologia para seleção e coleta de documentos. Revista ACB, 5(5), 131-144.

BOIKO, B. (2005). Content management bible. Indianapolis: Wiley Publ.

BUENO, W. C.. (2010). Comunicação cientifica e divulgação científica: aproximações e rupturas conceituais. Informação \& Informação, 15(1esp), 1-12.

CAMARGO, L. S. de A. de; \& VIDOTTI, S. A. B. G.. (2011). Arquitetura da informação: uma abordagem prática para o tratamento de conteúdo e interface em ambientes informacionais digitais. Rio de Janeiro: LTC.

CAPES. ([s.d.]). Tabela de Áreas de Conhecimento/Avaliação. Brasília, CAPES. Recuperado de: <https://bit.ly/2Y4SCeF>.

CASSOTTA, M. L. J.; LUCAS, A.; BLATTMANN, U.; \& GODOY VIERA, A. F.. (2017). Recursos do conhecimento: colaboração, participação e compartilhamento de informação científica e acadêmica. Informação \& Sociedade, 27(1).

CENDON, B. V.. (2001). Ferramentas de busca na Web. Ciência da Informação, 30, 3949.

CHOO, C. W.. (2003). A organização do conhecimento: como as organizações usam a informação para criar significado, construir conhecimento e tomar decisões. São Paulo: Editora SENAC.

CYSNEIRO, L. M.. (2013). Using i* to Elicit and Model Transparency in the Presence of Other Non-Functional Requirements: A Position Paper. In iStar (pp. 19-24).

CNPQ. ([s.d.]). Sobre a plataforma Lattes. Recuperado de: <http://lattes.cnpq.br $>$.

COULOURIS, G.; DOLLIMORE, J.; KINDBERG, T.; \& GORDON, B.. Distributed Systems. Concepts and design. 5. ed. Boston: Addison-Wesley.

DAMA. (2017). Data Management Body of Knowledge DAMA-DMBOK®. 2. ed. Westfield: Technics Publications.

DELABIO, F.; PIAI CEDRAN, D.; MORI, L.; \& MICHELLAN KIORANIS, N.. (2021). Divulgação científica e percepção pública de brasileiros (as) sobre ciência e tecnologia. Revista Insignare Scientia-RIS, 4(3), 273-290. 
DUARTE, J.. (2007). Comunicação pública. (LOPES, Boanerges, Org.). Gestão em comunicação empresarial: teoria e técnica. Juiz de Fora: Multimeios.

ELMASRI, R.; \& NAVATHE, S.. (2005). Sistemas de banco de dados. São Paulo: Pearson Addison Wesley.

MARCONDES, C. H.. (2001). Representação e economia da informação. Ciência da informação, 30(1), 61-70.

MARCONDES, C. H.; \& SAYÃO, L. F.. (2001). Integração e interoperabilidade no acesso a recursos informacionais eletrônicos em C\&T: a proposta da Biblioteca Digital Brasileira. Ciência da Informação, 30, 24-33.

MASSARANI, L.; \& PETERS, H. P.. (2016). Scientists in the public sphere: interactions of scientists and journalists in Brazil. Anais da Academia Brasileira de Ciências, 88, 1165-1175.

NISO. (2004). Noções básicas sobre metadados. Recuperado de: <https://bit.ly/3ypwqrL>.

PEREIRA, M.; \& KÖPTCKE, L.S.. (2009). Guia de Fontes Primárias: O Museu Nacional: seu público no Século XIX e início do Século XX. Rio de Janeiro: Fundação Oswaldo Cruz.

PINTO, A. E. S.. (2009). Jornalismo Diário: reflexões, recomendações, dicas e exercícios. São Paulo: Publifolha.

PRESSMAN, R. S.; \& MAXIM, B. R.. (2016). Engenharia de software: uma abordagem profissional. 8. ed. Porto Alegre: AMGH.

RODRIGUES, C.; \& BLATTMANN, U.. (2014). Gestão da informação e a importância do uso de fontes de informação para geração de conhecimento. Perspectivas em Ciência da Informação, 19, 4-29.

SANTAREM SEGUNDO, J. E.; SILVA, M. F.; \& MARTINS, D. L.. (2019). Revisitando a interoperabilidade no contexto dos acervos digitais. Informação \& Sociedade, 29(2).

SILVA, M. R. N.. (2011). O Arquivo e a Cibercultura. Guia de fonte sobre a história da prisão no Rio de Janeiro: 1830-1890 (pp. 1-12).

NASCIMENTO, M. de J.; \& SOMMER, C.. (2005). Jornalistas e o acesso à informação. Em Questão, 11(2), 425-452.

SUBRAMANYAM, K.; \& SUBRAMANYAM, B.. (1981). Scientific and Technical Information Resources. Boca Raton (EUA): CRC Press.

TEIXEIRA, T. M. C.; \& VALENTIM, M. L. P.. (2017). Processo de busca e recuperação de informação em ambientes organizacionais: uma reflexão teórica sobre a subjetividade da informação. Perspectivas em Ciência da Informação, 22(4), 8297.

TRAQUINA, N.. (2005). Teorias do Jornalismo, porque as notícias são como são. Florianópolis: Insular, 2. Ed..

\section{ABSTRACT:}

This article aims to present a report of the development of the Guia de Fontes@UFPR, a search tool for scientific information created by the Agency School of Public Communication and Scientific and Cultural Dissemination (AE) of the Federal University of Paraná (UFPR). In this context, the paper discusses information and scientific content management from an interdisciplinary point
\end{abstract}

of view and describes the development of the software covering Journalism, Information Management and Computing, areas of knowledge in which the methodological principles of the Guia de Fontes@UFPR are based. In conclusion, the work also presents the results under the Scientific Popularization. 
KEYWORDS: Information sources; Content Management; Web development; Journalism; Scientific Popularization.

\section{RESUMEN:}

Este texto presenta un análisis critica de las Este artículo tiene como objetivo presentar un informe de desarrollo de la Guia de Fontes@UFPR, una herramienta de búsqueda de información científica creada por la Agencia Escuela de Comunicación Pública y Difusión Científica y Cultural (AE) de la Universidad Federal de Paraná (UFPR). El trabajo hace una discusión de la información y de la gestión de contenido científica desde un punto de vista interdisciplinario. Además, describe el desarrollo del software a partir del Periodismo, de la Gestión de la Información y de la Informática, áreas del conocimiento en las cuales se buscan los principios metodológicos del Guia de Fontes@UFPR. En conclusión, el trabajo también presenta los resultados bajo la discusión de Difusión Científica.

PALABRAS-CLAVES: Fuentes de información; Gestión de Contenidos; Desarrollo web; Periodismo; Difusión Científica. 